\section{(6) OPEN ACCESS}

- Additional material is published online only. To view please visit the journal online (http://dx.doi.org/10.1136/ bjsports-2013-092816).

${ }^{1}$ Centre for Healthy and Safe Sport (CHASS) and the Australian Centre for Research into Injury in Sport and its Prevention (ACRISP), University of Ballarat, Ballarat, Victoria, Australia

${ }^{2}$ Centre for Musculoskeletal Research, Griffith Health Institute, Griffith University, Gold Coast, Queensland, Australia

${ }^{3}$ School of Sport Science, Exercise and Health, The University of Western Australia, Crawley, Western Australia, Australia

${ }^{4}$ School of Psychology and Exercise Science, Murdoch University, Murdoch, Western Australia, Australia

${ }^{5}$ School of Health Sciences, University of Ballarat, Mt Helen, Victoria, Australia ${ }^{6}$ Monash Injury Research Institute, Monash University, Clayton, Victoria, Australia

\section{Correspondence to} Professor Caroline F Finch, Centre for Healthy and Safe Sport, University of Ballarat, Ballarat, VIC 3353, Australia; c.finch@ballarat.edu.au

Accepted 21 August 2013 Published Online First 18 September 2013

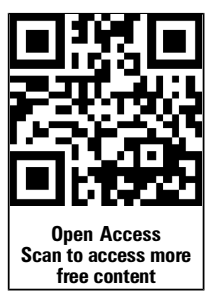

To cite: Finch $C F$, Doyle TLA, Dempsey AR, et al. Br J Sports Med 2014;48:702-707.

\title{
What do community football players think about different exercise-training programmes? Implications for the delivery of lower limb injury prevention programmes
}

\author{
Caroline F Finch, ${ }^{1}$ Tim LA Doyle, ${ }^{2,3}$ Alasdair R Dempsey, ${ }_{1}^{4}$ Bruce C Elliott, ${ }^{3}$ \\ Dara M Twomey, ${ }^{5}$ Peta E White, ${ }^{1}$ Kathy Diamantopoulou, ${ }^{6}$ Warren Young, ${ }^{5}$ \\ David G Lloyd ${ }^{2,3}$
}

\section{ABSTRACT}

Background Players are the targeted end-users and beneficiaries of exercise-training programmes implemented during coach-led training sessions, and the success of programmes depends upon their active participation. Two variants of an exercise-training programme were incorporated into the regular training schedules of 40 community Australian Football teams, over two seasons. One variant replicated common training practices, while the second was an evidencebased programme to alter biomechanical and neuromuscular factors related to risk of knee injuries. This paper describes the structure of the implemented programmes and compares players' end-of-season views about the programme variants.

Methods This study was nested within a larger groupclustered randomised controlled trial of the effectiveness of two exercise-training programmes (control and neuromuscular control (NMC)) for preventing knee injuries. A post-season self-report survey, derived from Health Belief Model constructs, included questions to obtain players' views about the benefits and physical challenges of the programme in which they participated.

Results Compared with control players, those who participated in the NMC programme found it to be less physically challenging but more enjoyable and potentially of more benefit. Suggestions from players about potential improvements to the training programme and its future implementation included reducing duration, increasing range of drills/exercises and promoting its injury prevention and other benefits to players.

Conclusions Players provide valuable feedback about the content and focus of implemented exercise-training programmes, that will directly inform the delivery of similar, or more successful, programmes in the future.

\section{BACKGROUND}

For many years, researchers have investigated exercise-training strategies to potentially reduce the risk of anterior cruciate ligament (ACL) and other knee injuries in sport. Such injuries often occur during sporting tasks involving rapid changes of direction, rapid reduction in running speed and/or single-legged landing. ${ }^{1-4}$ Exercise-training strategies have attempted to teach athletes safe ways to perform these actions through approaches that can be broadly categorised as incorporating technique, plyometric, balance and/or resistance training. ${ }^{5}$
Most traditional football training sessions are designed to develop technical and tactical skills, whereas fitness training sessions emphasise the development of strength, power and/or endurance. ${ }^{6}$ To prevent injury, there is a need for training sessions to incorporate different neuromuscular and biomechanical approaches-including technique, balance training and plyometric training-towards learning safer ways of performing known tasks directly relevant to the sport. ${ }^{7-17}$

Evidence of the likely benefits of these different methods has come from a range of laboratory and field-based research studies. ${ }^{5} 710-19$ Although most evidence is from elite/high-performance athletes or women only, it is likely that it applies equally to other sports participants, where the same mechanisms of injury occur. ${ }^{20} \mathrm{~A}$ key limitation of the existing literature, however, is that few papers have published full details of their experimental exercise programmes and it has been difficult for others to replicate findings, or to implement the same programmes, in other settings. This contributes to the known implementation challenges of intervention adaptation and fidelity. ${ }^{21} 22$ Of course, neuromuscular training programmes aimed at community participants require effectiveness evidence when they are based on programmes previously developed for, and tested in, high performance sport. The pros and cons of different programme adaptations for community sport also need to be assessed and the likely barriers to, or drivers for, sustained adoption of these programmes by community players need to be identified and addressed, before they can be widely implemented. ${ }^{23} 24$

The first aim of this paper was to describe two variants of an exercise-training programme that were incorporated into the regular training schedules of 40 community Australian Football (AF) teams, over two consecutive playing seasons. One variant replicated common existing training practices (the control programme). The second variant (the neuromuscular control (NMC) programme) was derived from the evidence-base generated from a range of different studies that also included research on exercises in laboratory-based studies and population-based studies that were consistent with the mechanisms of injury and shown to alter biomechanical and/or neuromuscular factors related to decreasing the risk of sustaining injuries to the knee, particularly the ACL. 
Successful exercise-training programmes require players to undertake them. This requires players to appreciate programme benefits, weighed against any perceived barriers that they may have towards undertaking them. ${ }^{24}$ The second aim of this paper is to compare players' end-of-season views about these two programmes, to provide important information from the targeted end-users to inform the wide-scale implementation of similar programmes in the future. This study was nested within a larger group-clustered randomised controlled trial (RCT) of the effectiveness of the two programmes in preventing knee injuries. ${ }^{25} 26$

\section{METHODS}

At community-level AF, most players undertake bi-weekly training sessions to prepare for their weekend games. ${ }^{25}$ These sessions focus on team tactics, technique modifications to enhance game skills and drills (aerobic, anaerobic and muscular endurance) to enhance fitness for the sport. Typically, these training programmes do not focus on specific exercises to reduce the risk of injury. ${ }^{6}$ The two programmes were designed to take place during the specific warm-up time of the training sessions, for approximately $20 \mathrm{~min}$; as such their intensity was purposely designed not to be overly strenuous. Prior to conduct of these training programmes, players undertook a general warm-up including light running and stretching activities.

\section{Control training programme}

The control training programme was designed with the primary goal of mimicking common training programmes used in community AF. This focused on drills for running, jumping, landing, change of direction (COD) and agility. The difficulty of the exercises was graduated so that their demands increased over the season. Instruction on landing, agility or change-of-direction technique and balance tasks were not included in the control programme. Full details of the components of the programme are given in the online supplementary appendix 1 .

\section{Development of the NMC training programme}

The evidence-base for the NMC programme aligned with the Translating Research into Prevention Practice framework, ${ }^{27}$ which states that a firm understanding of injury mechanisms is first required, and subsequent experimental evidence on countering any identified mechanisms should be used to guide potential injury prevention measures. The NMC programme was based on the then available scientific literature directly pertaining to ACL injuries in $\mathrm{AF}^{2} 891819$ but also borrowed from a range of ACL injury studies pertaining to other sporting codes. ${ }^{1} 471011 \quad 14-17$ This experimental evidence came from a range of different types of investigations ${ }^{5} 2028$ that included cadaveric-based research, ${ }^{29-32}$ computational models, ${ }^{33}$ analyses of videos of in-game ACL injuries, ${ }^{1-4}$ laboratory experiments of

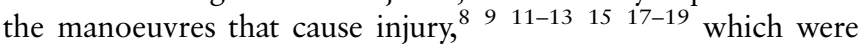
supported by interventions that tested the effect of exercise/ neuromuscular training programmes on ACL injury prevention. $^{7} 10{ }^{14}$ Specifically, the NMC programme was designed to: fit within the real-world time confines of community-AF training sessions; improve sidestepping and/or single-leg landing technique in order to lower flexion, valgus and internal rotation moments at the $\mathrm{knee}^{34}$; and increase muscular support of the knee. The programme incorporated balance, plyometric and technique activities.

The NMC programme aimed to ensure that correct technique was utilised during both sidestep cutting and landing movements. Specifically for sidestepping, the aim was to achieve an upright forward facing torso with close foot placement, and increased knee flexion with a knee-over-toe posture. ${ }^{18}$ For landing, the players were instructed to keep their torso upright and to increase knee flexion. ${ }^{19}$ Plyometric and balance training were used to improve stability and control of whole body movements to reduce the valgus and internal rotation moments at the knee $^{8} 19$ and increase the muscular support of these moments through both an increase in strength and co-contraction of muscles. $^{5} 28$ Even in the plyometric and balance training, players were instructed to keep their torso upright, to increase knee flexion with knee-over-toe postures. All of the balance, plyometric and technique elements were deemed to be the guiding principles of the NMC training programme.

Online supplementary appendix 2 gives full details of the NMC programme including its progressions, exercise components and repetition/sets structure. In total, there were 20 exercises used throughout the season of four broad types: balance, basic movement, COD/agility and landing/mini-tramp activities. The programme included some progressions whereby the intensity and difficulty of the programme varied, beginning with less strenuous tasks and progressing in difficulty. ${ }^{35} \mathrm{~A}$ prime focus was on getting the players to perform the required exercises correctly and on eliciting desired neuromuscular and biomechanical changes.

For each exercise, key instructional points were emphasised by coaching staff, who were trained by authors (TD and DT) in how to deliver the training programmes. Key points were made specific to the exercise tasks and included cues from the coaches to achieve the desired techniques: avoid extraneous limb movement; concentrate on balance not the task; do not lean excessively with the trunk; keep the arms close to body; keep the contact foot in line with hips; maintain balance after task; maintain leg (shank) stability. These points often overlapped across exercises and built on each other throughout the season.

\section{Conduct of the Preventing Australian Football Injuries with eXercise RCT}

This study was nested within the conduct and evaluation of a group-clustered RCT of the effectiveness of exercise programmes in community AF: the Preventing Australian Football Injuries with eXercise (PAFIX) study. Full details of the study design, data collection protocol and accuracy of the data collection methods are published elsewhere. ${ }^{26} 36$ Briefly, PAFIX was a two arm group-clustered RCT conducted in community AF during the 2007 and 2008 playing seasons. Eighteen clubs from two Australian states (Victoria and Western Australia) nominated 40 teams to participate in the study and these groups of players were randomised to one of the two intervention arms, corresponding to the two programmes (control and NMC). All teams from the same club were randomised to the same study arm. A trained primary data collector was assigned to each team to deliver the training programme and collect data for the duration of the season. ${ }^{36}$ The study was approved by two Institutional Ethics Committees.

In both states, the programmes were started during preseason ( 8 weeks before the first game), delivered twice per week and continued in this fashion for the first half of the 18 round season (table 1). From season week 11, teams entered a maintenance phase and the programme delivery frequency was reduced to once per week. In total, teams participated in their allocated programme for 28 weeks, including two bye weeks. If teams made the finals series, their programme continued to run once per week for the remaining weeks up to a maximum of 4 weeks. Mesocycles lasted between 3 and 5 weeks when the training was twice per week (table 1). 
Table 1 Intervention delivery plan

\begin{tabular}{lll}
\hline Week & Programme & Frequency \\
\hline Weeks 1-4 preseason & Pre 1 & 2/week \\
Weeks 5-8 preseason & Pre 2 & 2/week \\
Weeks 1-5 & In-season 1 & 2/week \\
Weeks 6-10 & In-season 2 & 2/week \\
Weeks 11-14 & Maintenance 1 & $1 /$ week \\
Weeks 15-18 & Maintenance 2 & $1 /$ week \\
Weeks 19-22 & Maintenance 3 & $1 /$ week \\
\hline
\end{tabular}

Teams of players were randomly allocated to each trial arm and then players were recruited from randomised teams. Players were at least 18 years of age by the end of February in the year they were enrolled, and attended at least one training session in the 8 -week preseason period or during the first 5 weeks of the season. Players who had not participated in any training sessions were excluded. Details of player attendance and their adoption of the programmes have been published elsewhere. ${ }^{25}$

\section{End-of-season player survey}

All players were invited to complete an end-of-season survey about their views on the specific training programme variant in which they had participated. The survey questions, which were worded identically for both study arms and included a mix of closed and open-ended questions, were derived from Health Belief Model constructs and based on an earlier survey used by the authors. ${ }^{24}$ The survey was administered over a 2-week period at all team training sessions at the end of the season (August-September). Players were encouraged to complete the surveys at a training session.

All surveys were precoded and double-entered. Thematic coding was applied to player responses to two open-ended questions. Eleven themes emerged from the question addressing how the training programme could be improved, and nine from the question addressing why players would want to participate in a similar training programme in the future. Most players provided brief single-idea responses but when they provided more than one, each response was coded separately. All data were analysed using the statistical software package, IBM SPSS Statistics V.20.
For each question, cross-tabulation tables of frequencies and percentages were produced. A two-sided Pearson $\chi^{2}$ test of association was used to ascertain any significant $(p<0.05)$ differences in player responses across allocated programmes.

\section{RESULTS}

Overall, 1564 players participated in the PAFIX RCT. Of these, 442 players (or $28.3 \%$ of the enrolled PAFIX players) completed the voluntary post-season player survey. The response rate was the same in the two groups, with 192 players responding to the survey in relation to the NMC programme (of 679 players, 28.3\%) and 250 (of 885 players, 28.2\%) for the control programme.

The players from different programmes perceived different benefits (table 2). Significantly fewer NMC players agreed that their programme improved fitness than did control players. Conversely, a significantly greater proportion of NMC players, than control players, agreed that a benefit of this form of training programme was that it was more enjoyable than that previously undertaken.

Fewer NMC players thought their programme was harder than previous training, compared with control players (table 3 ). NMC players also thought that their programme was, 'more enjoyable than previous training' and 'better at preventing injury'.

When asked specifically about the intensity of their training, there was significantly proportionally more NMC players, than control players, who rated their programme as being of low intensity $\left(\chi_{2}^{2}=62.919 ; \mathrm{p}<0.001\right)$. Significantly fewer NMC players thought their programme was too long compared with the control group $\left(\chi_{3}^{2}=12.534 ; \mathrm{p}=0.006\right)$.

Players were asked if they thought their training programme could be improved in any way, 94 players $(21.3 \%)$ gave specific suggestions for how this could be done. The most frequent responses for improvements to the programme were that it could be shorter in length (21\% for NMC; $29 \%$ for control) and it could have more variety in the drills/exercises $(16 \%$ for NMC; $18 \%$ for control).

Finally, the players were asked if they would choose to participate in a similar training programme in the future, and if so, why? Of the 209 players (47.2\% of the survey respondents) who answered yes, 116 (56\%) players gave reasons (table 4); 'preventing injury' (33\% for NMC; $20 \%$ for control) and

Table 2 Players' opinions about the benefits of the exercise training they participated in: control $(n=250)$ or neuromuscular control (NMC; $n=192$ )

\begin{tabular}{|c|c|c|c|c|c|c|}
\hline \multirow[b]{2}{*}{ Player response } & \multirow[b]{2}{*}{ Programme } & \multicolumn{5}{|l|}{ Question asked } \\
\hline & & $\begin{array}{l}\text { It improved my } \\
\text { performance }\end{array}$ & $\begin{array}{l}\text { It reduced my risk } \\
\text { of injury }\end{array}$ & $\begin{array}{l}\text { It increased my } \\
\text { enjoyment of the game }\end{array}$ & $\begin{array}{l}\text { It improved my } \\
\text { fitness }\end{array}$ & $\begin{array}{l}\text { It made me enjoy } \\
\text { training more }\end{array}$ \\
\hline Strongly disagree & $\begin{array}{l}\text { NMC } \\
\text { Control }\end{array}$ & $\begin{array}{r}5(2.6 \%) \\
14(5.6 \%)\end{array}$ & $\begin{array}{r}5(2.6 \%) \\
16(6.4 \%)\end{array}$ & $\begin{array}{r}9(4.7 \%) \\
23(9.2 \%)\end{array}$ & $\begin{array}{r}7(3.6 \%) \\
13(5.2 \%)\end{array}$ & $\begin{array}{r}8(4.2 \%) \\
22(8.9 \%)\end{array}$ \\
\hline Disagree & $\begin{array}{l}\text { NMC } \\
\text { Control }\end{array}$ & $\begin{array}{l}24(12.5 \%) \\
36(14.4 \%)\end{array}$ & $\begin{array}{l}15(7.8 \%) \\
24(9.6 \%)\end{array}$ & $\begin{array}{l}36(18.8 \%) \\
51(20.5 \%)\end{array}$ & $\begin{array}{l}34(17.7 \%) \\
32(12.9 \%)\end{array}$ & $\begin{array}{l}29(15.1 \%) \\
51(20.7 \%)\end{array}$ \\
\hline $\begin{array}{l}\text { Neither agree nor } \\
\text { disagree }\end{array}$ & $\begin{array}{l}\text { NMC } \\
\text { Control }\end{array}$ & $\begin{array}{r}96(50.0 \%) \\
108(43.2 \%)\end{array}$ & $\begin{array}{l}59(30.7 \%) \\
77(30.8 \%)\end{array}$ & $\begin{array}{r}98(51.0 \%) \\
113(45.4 \%)\end{array}$ & $\begin{array}{l}74(38.5 \%) \\
69(27.7 \%)\end{array}$ & $\begin{array}{r}84(43.8 \%) \\
111(45.1 \%)\end{array}$ \\
\hline Agree & $\begin{array}{l}\text { NMC } \\
\text { Control }\end{array}$ & $\begin{array}{l}61(31.8 \%) \\
82(32.8 \%)\end{array}$ & $\begin{array}{c}97(50.5 \%) \\
110(44.0 \%)\end{array}$ & $\begin{array}{l}43(22.4 \%) \\
51(20.5 \%)\end{array}$ & $\begin{array}{r}66(34.4 \%) \\
116(46.6 \%)\end{array}$ & $\begin{array}{l}62(32.3 \%) \\
50(20.3 \%)\end{array}$ \\
\hline Strongly agree & $\begin{array}{l}\text { NMC } \\
\text { Control }\end{array}$ & $\begin{array}{r}6(3.1 \%) \\
10(4.0 \%)\end{array}$ & $\begin{array}{l}16(8.3 \%) \\
23(9.2 \%)\end{array}$ & $\begin{array}{r}6(3.1 \%) \\
11(4.4 \%)\end{array}$ & $\begin{array}{l}11(5.7 \%) \\
19(7.6 \%)\end{array}$ & $\begin{array}{r}9(4.7 \%) \\
12(4.9 \%)\end{array}$ \\
\hline $\begin{array}{l}\text { Statistical comparison } \\
\text { programmes }\end{array}$ & across & $\chi_{4}^{2}=3.909(p=0.418)$ & $\chi_{4}^{2}=4.765(p=0.312)$ & $\chi_{4}^{2}=4.639(p=0.326)$ & $\chi_{4}^{2}=10.717(p=0.030)$ & $\chi_{4}^{2}=11.554(p=0.021)$ \\
\hline
\end{tabular}

Responses to questions are given as frequencies and percentages of all responding players in each programme. 


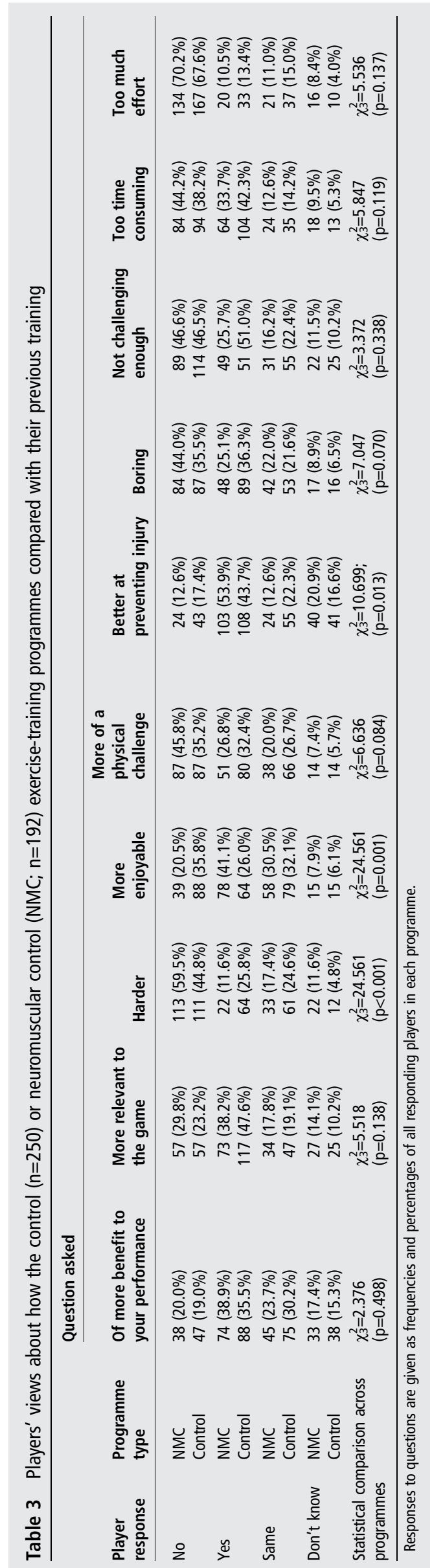

'being a beneficial program' (20\% for NMC; $12 \%$ for control) which were the most frequently stated reasons.

\section{DISCUSSION}

There is increasing awareness of the challenges of implementing evidence-based programmes in the delivery context of community sport. ${ }^{24} 273738$ While there is a need for strong evidence to underpin such programmes, the quality of evidence supporting exercise-training programmes for lower limb injury prevention is variable. ${ }^{50}$ Most studies have not provided specific implementation details and this has limited the extent to which similar programmes can confidently be applied in other settings. This paper is one of very few to provide specific information about the content and delivery of an exercise-training programme aimed at lower limb injury prevention in any form of community football. In doing so, it provides a strong basis from which programme adaptations could be made and tested to inform future programmes.

Both programme variants were designed using typical programming principles, such as progressive overload and periodisation. For example, the intensity and difficulty of the exercises increased and fluctuated throughout the season. In the NMC programme, simple exercises such as 'squares' were programmed in the first weeks and mini-tramp exercises were not introduced until week 9, that is, the more physically challenging and demanding exercises were only introduced after a suitable base and proficiency had been established.

Having an evidence-based programme that can be adapted for different delivery settings is a necessary condition for broader implementation, but it is not sufficient. In the end, the programmes need to be both adopted by coaches or fitness/skills trainers as the delivery agents and undertaken by players as the target end-user beneficiaries of such programmes. ${ }^{39}$ In a previous study, AF players were asked about their views of participating in a specific lower-limb injury prevention exercise-training programme for their sport before they had participated in such a programme. ${ }^{24}$ The views of those players were generally that any exercise-training programme for injury prevention should be implemented as part of routine football activities and strongly associated with training benefits. This paper adds to this by presenting views from players after exposure to the delivery of exercise-training programmes over a preseason and full season period. By comparing players randomised to a control training programme with those who participated in an evidence-based NMC programme, particular advantages of the latter are identified. This information provides very important qualitative information according to the implementation (I) and likely maintenance (M) dimensions of the RE-AIM Framework $^{40}$ for evaluating implementation success. Of course, information about the effectiveness of the programmes in preventing injuries is also required, and the injury prevention benefits of the NMC programme are to be reported elsewhere.

Compared with control players, fewer NMC players thought that their programme improved fitness or perceived it to be of high intensity, which is as expected given the NMC was of lower intensity than the control programme. It is worth pointing out that the implemented programmes were not aimed at improving fitness and hence were, by design, not of high intensity; they were intended to be undertaken as a warm-up before regular training components. Nonetheless, the same NMC players thought that their programme made training more enjoyable and this possibly reflects the novelty of the equipment and specific exercises for many players. Overall, compared with previous training programmes they had participated in, the 
Table 4 Themes coded from players' free-text suggestions for improvements to the training programmes and stated motivators for their ongoing participation in a similar training programme

\begin{tabular}{|c|c|c|c|}
\hline & \multirow[b]{2}{*}{ Response } & \multicolumn{2}{|l|}{ Programme } \\
\hline & & $\begin{array}{l}\text { NMC } n(\% \text { of } \\
\text { responders to question) }\end{array}$ & $\begin{array}{l}\text { Control } n \text { (\% of } \\
\text { responders to question) }\end{array}$ \\
\hline $\begin{array}{l}\text { Suggested improvements that could be } \\
\text { made to the training programme } \\
\chi_{9}^{2}=8.325 p=0.502 \\
93 \text { players }(N M C=38 \text {, control }=55 \text { ) } \\
\text { responded to this question }\end{array}$ & $\begin{array}{l}\text { Shorter in length } \\
\text { More variety in drills/exercises } \\
\text { Higher intensity/more active } \\
\text { More specific to football/game play } \\
\text { Better/frequent explanation of drills/benefits of programme } \\
\text { Gradual exposure to sprints } \\
\text { More equipment } \\
\text { More enjoyable/interesting } \\
\text { More stretching/core/balance/interval training } \\
\text { Other/non-specific }\end{array}$ & $\begin{array}{l}8(21) \\
6(16) \\
6(16) \\
2(5) \\
2(5) \\
0 \\
1(3) \\
3(8) \\
2(5) \\
8(21)\end{array}$ & $\begin{array}{l}16(29) \\
10(18) \\
2(4) \\
2(4) \\
5(9) \\
4(7) \\
1(2) \\
4(7) \\
2(4) \\
9(16)\end{array}$ \\
\hline $\begin{array}{l}\text { Reasons for future participation in a } \\
\text { similar training programme } \\
\chi_{8}^{2}=12.157 \mathrm{p}=0.144 \\
116 \text { players }(N M C=51, \text { control }=65 \text { ) } \\
\text { responded to this question }\end{array}$ & $\begin{array}{l}\text { Prevent injury } \\
\text { Beneficial } \\
\text { Improves fitness } \\
\text { Good warm-up/prepares body for training } \\
\text { More interesting/good change from normal warm-up } \\
\text { Helps with ability/balance } \\
\text { Good/enjoyable } \\
\text { Benefits performance/makes me a better player } \\
\text { Other/non-specific }\end{array}$ & $\begin{array}{l}17(33) \\
10(20) \\
0 \\
4(8) \\
7(14) \\
4(8) \\
3(6) \\
0 \\
6(12)\end{array}$ & $\begin{aligned} 13 & (20) \\
8 & (12) \\
7 & (11) \\
10 & (15) \\
7 & (11) \\
3 & (5) \\
7 & (11) \\
1 & (2) \\
9 & (14)\end{aligned}$ \\
\hline
\end{tabular}

Responses given as frequencies and percentages of each group who answered this question.

NMC, neuromuscular control.

NMC players were more likely to consider their programme as being more enjoyable, less hard and better at preventing injury than did control players.

Having players participate in a programme is only the first stage in ensuring long-term injury prevention goals. As reported elsewhere, these players had variable attendance at training sessions across the season, but if they did attend training, they were highly likely to participate in the programme. ${ }^{25}$ However, for long-term injury prevention goals, players need to adopt these behaviours consistently and attention needs to be given towards likely drivers of maintenance of player participation. ${ }^{40}$ For this reason, players were invited to suggest improvements to the programme. The most common suggestion was for the programmes to be decreased in length, presumably, so players could move on to what they considered the main focus of their training to be, that is, football-specific skills and fitness development. This was unexpected feedback, as the programmes were designed to be the length of the usual warm-up periods before normal training. The trialled programmes were designed to last for up to $20 \mathrm{~min}$, though most were completed in $15 \mathrm{~min}$. The final 2-3 warm-up activities included match-specific activities for dual use of the time (ie, for both warm-up and basic skill training).

The second most common suggestion was to have more variety in the drills/exercises. This would certainly be advantageous to ensure players are neither bored nor under-challenged by the exercises and to help reduce player dropout. There is a role for coaching staff to engage with players actively in this aspect. The specific training drills shown in the appendices provide a starting point from which coaches can consider exercise variations. However, it will be important that modifications, if any, maintain the principles of training programmes and are delivered with high fidelity to ensure that intended injury prevention benefits flow. Such changes should be made by personnel qualified to design training programmes and those with suitable experience to ensure that any modified programme delivers the same benefits as the original programme. Importantly, any modified programme must still include all three components of balance, plyometrics and technique and ensure instruction points/cues are used to emphasise correct sidestep and landing movements.

It is particularly pleasing that the highest proportion of players, from both programmes, indicated that the major reason to motivate them to undertake their training programmes in the future was its likely injury prevention benefits. The fact that this benefit was a stronger motivator for the NMC players suggests that, at the very least, they perceived a sense of protection from injury for having completed the NMC programme.

This study has several limitations. It was nested within a larger RCT and so the number of players available to complete the end-of-season survey was limited by the number who attended training sessions at the end of the season. Unfortunately we have no information about why players did or did not attend training sessions towards the end of the season, but one possible reason for non-attendance could be related to the likelihood of the players' teams progressing to the final series. $^{25}$ The overall response rate, in proportion to all enrolled trial players, was $28 \%$ but as this was consistent across study arms there was unlikely to be a differential response according to the nature of the specific training programme delivered. However, we have previously described attendance of the players in the training sessions throughout the season and shown that at most only $40 \%$ of them attended training in the final 4 weeks of the season, when this survey was conducted. ${ }^{25}$ Taking this into account, the survey response rate is close to $71 \%$ of all players who attended training at the end of the season, indicating a good capture of players' views in the survey. Unfortunately, we do not have information about the nonresponders' views of the training programmes and it is possible that they could be different to what is reported here.

All information collected in the surveys reflect the subjective views of the players and their self-assessments of the training programmes. As such, their rating of programme intensity, etc will be subjective and it was not possible to confirm this with 
direct observation. Suggestions about how to improve the programmes and their delivery were only given by a subset of players. Nonetheless, suggestions they gave about what would motivate them to continue with the programme will be valuable for informing future prevention programmes.

In summary, this paper has presented details of two variants of an exercise-training programme and the views of the players who participated in either form. Players are the targeted end-users and beneficiaries of exercise-training programmes implemented during coach-led training sessions. Their views about the programmes are important because they are necessary for directly informing the delivery of similar, or more successful, programmes in the future. As the programmes are delivered by coaching staff, establishing the views of coaches, and how they relate to those of their players, will also be important. ${ }^{6}$

\section{What are the new findings}

- In order to ensure sustained adoption of evidence-based exercise-training programmes, views need to be obtained from players (the end-beneficiaries) as to the likely barriers against, or drivers, of this.

- Compared with players who participated in standard training programmes, players who participate in a neuromuscular control (NMC) exercise-training programme find it less physically challenging but more enjoyable and potentially of more benefit than previous programmes. This stresses the importance of training in community sports.

- Future neuromuscular training programmes can be modelled on the detailed programme provided in this paper but, to maximise player engagement with them, consideration should be given to its timing and intensity within the overall training session, increasing the range of drills/exercises that can be undertaken and widely promoting its injury prevention and other benefits to players

\section{How might it impact on clinical practice in the near}

future

- The proposed neuromuscular control (NMC) exercise-training programme has sufficient detail to be directly implemented, especially in Australian football.

- The training principles of the NMC programme can be adapted to other sporting codes and motivate the development of new training programmes.

- New designs of injury prevention programmes may need to increase difficulty of progressions.

- Emphasising the injury prevention benefits of training programmes to players will ensure uptake and adherence.

Acknowledgements Angela McGlashan is thanked for her contributions as research assistant on this project through the conduct of the surveys in the Victorian sample and for helping to establish the survey database.

Contributors CFF, DGL and BCE conceived and designed the PAFIX study. CFF, TLAD and ARD took the lead roles in writing the paper. Each coauthor contributed to the writing of the paper and/or provided significant editorial inputs. DMT and TLAD recruited the clubs and players and oversaw the delivery of the programme. TLAD designed the training programme components, under direction from DGL and
BCE. TLAD administered the surveys in the WA sample. KD and PEW undertook database management, data coding and analysis, and developed the analysis plan in conjunction with CFF. WY contributed to the interpretation of the data.

Funding The PAFIX study was funded by a nationally competitive research grant from the (Australian) National Health and Medical Research Council (NHMRC)— Project ID 400937; The Australian Centre for Research into Injury in Sport and its Prevention (ACRISP) is one of the International Research Centres for Prevention of Injury and Protection of Athlete Health supported by the International Olympic Committee (IOC). CFF was supported by an NHMRC Principal Research Fellowship (ID: 565900).

Competing interests CFF, DGL and BCE were the project chief investigators. DMT and TLAD were supported by research fellowships, and AM received a PhD scholarship, through the grant during the active project phase.

Ethics approval University of Ballarat and University of Western Australia Human Ethics Committees.

Provenance and peer review Not commissioned; externally peer reviewed.

Data sharing statement No data are available, but the survey can be provided, upon request.

Open Access This is an Open Access article distributed in accordance with the Creative Commons Attribution Non Commercial (CC BY-NC 3.0) license, which permits others to distribute, remix, adapt, build upon this work non-commercially, and license their derivative works on different terms, provided the original work is properly cited and the use is non-commercial. See: http://creativecommons.org/ licenses/by-nc/3.0/

\section{REFERENCES}

1 Boden BP, Dean GS, Feagin JA Jr, et al. Mechanisms of anterior cruciate ligament injury. Orthopedics 2000;23:573-8.

2 Cochrane J, Lloyd D, Buttfield A, et al. Characteristics of anterior cruciate ligament injures in Australian football. J Sci Med Sport 2007:10:96-104.

3 Krosshaug T, Nakamae A, Boden BP, et al. Mechanisms of anterior cruciate ligament injury in basketball: video analysis of 39 cases. Am J Sports Med 2007;35:359-67.

4 Olsen OE, Myklebust G, Engebretsen L, et al. Injury mechanisms for anterior cruciate ligament injuries in team handball: a systematic video analysis. Am J Sports Med 2004:32:1002-12.

5 Donnelly CJ, Elliott BC, Ackland TR, et al. An anterior cruciate ligament injury prevention framework: incorporating the recent evidence. Res Sports Med 2012:20:239-62.

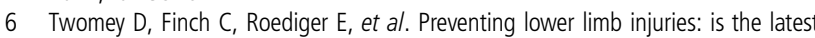
evidence being translated into the football field? J Sci Med Sport 2009;12:452-6.

7 Caraffa A, Cerulli G, Projetti M, et al. Prevention of anterior cruciate ligament injuries in soccer: a prospective controlled study of proprioceptive training. Knee Surg Sp Truam Arthro 1996;4:19-21.

8 Cochrane JL, Lloyd DG, Besier TF, et al. Training affects knee kinematics and kinetics in cutting maneuvers in sport. Med Sci Sports Exerc 2010;42:1535-44.

9 Dempsey A, Lloyd D, Elliott $B$, et al. The effect of technique change on knee loads during sidestep cutting. Med Sci Sports Exerc 2007;39:1765-73.

10 Hewett TE, Lindenfeld TN, Riccobene JV, et al. The effect of neuromuscular training on the incidence of knee injury in female athletes. A prospective study. Am J Sports Med 1999;27:699-706.

11 Hewett TE, Stroupe AL, Nance TA, et al. Plyometric training in female athletes. Decreased impact forces and increased hamstring torques. Am J Sports Med 1996;24:765-73.

12 Holm I, Fosdahl MA, Friis A, et al. Effect of neuromuscular training on proprioception, balance, muscle strength, and lower limb function in female team handball players. Clin J Sport Med 2004;14:88-94.

13 Irmischer BS, Harris C, Pfeiffer RP, et al. Effects of a knee ligament injury prevention exercise program on impact forces in women. J Strength Cond Res 2004;18:703-7.

14 Mandelbaum BR, Silvers HJ, Watanabe DS, et al. Effectiveness of a neuromuscular and proprioceptive training program in preventing anterior cruciate ligament injuries in female athletes: 2-year follow-up. Am J Sports Med 2005;33:1003-10.

15 Myer GD, Ford KR, Brent JL, et al. The effects of plyometric vs. dynamic stabilization and balance training on power, balance, and landing force in female athletes. J Strength Cond Res 2006;20:345-53.

16 Myklebust G, Engebretsen L, Braekken IH, et al. Prevention of anterior cruciate ligament injuries in female team handball players: a prospective intervention study over three seasons. Clin J Sport Med 2003;13:71-8.

17 Paterno MV, Myer GD, Ford KR, et al. Neuromuscular training improves single-limb stability in young female athletes. JOSPT 2004;34:305-16.

18 Dempsey A, Lloyd D, Elliott B, et al. Changing sidestep cutting technique reduces knee valgus loading. Am J Sports Med 2009:37:2194-200. 
19 Dempsey AR, Elliott BC, Munro BJ, et al. Whole body kinematics and knee moments that occur during an overhead catch and landing task in sport. Clin Biomech 2012;27:466-74

20 Andrew A, Gabbe B, Cook J, et al. Could targeted exercise programmes prevent lower limb injury in community Australian Football? Sports Med 2013;43:751-63.

21 Carvalho M, Honeycutt S, Escoffery C, et al. Balancing fidelity and adaptation: implementing evidence-based chronic disease prevention programs. J Public Health Manag Pract 2013;43:751-63.

22 Finch C. Chapter 35. Implementing and evaluating interventions. In: Baker S, Li G. eds. Injury research: theories, methods, and approaches. New York: Springer, 2012:619-39.

23 Donaldson A, Finch C. Planning for implementation and translation: seek first to understand the end users perspective. Br J Sports Med 2012;46:306-7.

24 Finch $C F$, White $P$, Twomey $D$, et al. Implementing an exercise-training programme to prevent lower-limb injuries: considerations for the development of a randomised controlled trial intervention delivery plan. Br J Sports Med 2011;45:791-6.

25 Finch C, Diamantoplou K, Young W, et al. The reach and adoption of coach-led exercise training program in community football. Br J Sports Med 2014;48:718-23.

26 Finch C, Lloyd D, Elliott B. The Preventing Australian Football Injuries with eXercise (PAFIX) study —a group randomised controlled trial. Inj Prev 2009;15:e1. 10.1136/ ip.2008.021279

27 Finch C. A new framework for research leading to sports injury prevention. J Sci Med Sport 2006:9:3-9.

28 Lloyd D. Rationale for training programs to reduce anterior cruciate ligament injuries in Australian football. JOSPT 2001:31:645-54

29 Markolf KL, Burchfield DM, Shapiro MM, et al. Combined knee loading states that generate high anterior cruciate ligament forces. J Orthop Res 1995;13:930-5.
30 Meyer EG, Haut RC. Excessive compression of the human tibio-femoral joint causes ACL rupture. J Biomech 2005;38:2311-16.

31 Meyer EG, Haut RC. Anterior cruciate ligament injury induced by internal tibial torsion or tibiofemoral compression. J Biomech 2008;41:3377-83.

32 Wu JL, Seon JK, Gadikota HR, et al. In situ forces in the anteromedial and posterolateral bundles of the anterior cruciate ligament under simulated functional loading conditions. Am J Sports Med 2010;38:558-63.

33 Shin CS, Chaudhari AM, Andriacchi TP. Valgus plus internal rotation moments increase anterior cruciate ligament strain more than either alone. Med Sci Sports Exerc 2011:43:1484-91.

34 Donnelly C, Elliott B, Doyle T, et al. Changes in knee joint biomechanics following balance and technique training and a season of Australian football. $\mathrm{Br}$ J Sports Med 2012;46:917-22.

35 Wathen D, Baechle T, Earle R. Periodization. In: Baechle T, Earle R. eds. Essentials of strength training and conditioning. Champaign, IL: Human Kinetics for the National Strength and Conditioning Association, 2008:507-552.

36 Twomey D, Finch C, Doyle T, et al. Level of agreement between field-based data collectors in a large scale injury prevention randomised controlled trial. J Sci Med Sport 2011;14:121-5.

37 Finch $C$. No longer lost in translation-the art and science of sports injury prevention implementation research. Br J Sports Med 2011;45:1253-7.

38 Soligard T, Nilstad A, Steffen K, et al. Compliance with a comprehensive warm-up programme to prevent injuries in youth football. Br J Sports Med 2011;44: 787-93.

39 Donaldson A, Finch CF. Applying implementation science to sports injury prevention. Br J Sports Med 2013;47:473-5.

40 Finch $C F$, Donaldson $A$. A sports setting matrix for understanding the implementation context for community sport. Br J Sports Med 2010;44:973-8. 